\title{
Experimental validation of the direct strength method for shear spans with high aspect ratios
}

\author{
Song Hong Pham*, Cao Hung Pham*, Colin A. Rogers** and Gregory J. Hancock* \\ * School of Civil Engineering, the University of Sydney, Australia \\ e-mails: songhong.pham@sydney.edu.au, caohung.pham@sydney.edu.au, gregory.hancock@sydney.edu.au \\ ** Department of Civil Engineering and Applied Mechanics, McGill University, Canada \\ e-mail: colin.rogers@mcgill.ca
}

\begin{abstract}
Shear behaviour of cold-formed steel beams with an aspect ratio (shear-span / web-depth) of 1.0 has been studied thoroughly, mainly using central point load tests. However, for beams with higher aspect ratios, the effect of bending causes a reduction of shear capacity and alters the failure modes. This paper introduces a new test setup, the dual actuator test rig, which is equipped with two actuators moving independently at customizable displacement rates to control and minimize applied bending moments in the shear spans of interest. Shear strength close to pure shear capacity can be therefore reached even at an aspect ratio of 2.0. Experimental series recently performed at the University of Sydney on channel section members using the new test configuration is presented. The experimental results together with other available experimental data are combined and used to validate and re-calibrate the Direct Strength Method design formulae incorporated in the AISI S100:2016 Specification and the AS/NZS 4600:2018 Standard.
\end{abstract}

Keywords: Shear strength, shear test, direct strength method, cold-formed steel structures.

\section{INTRODUCTION}

Cold-formed steel (CFS) structures are widely used in the construction industry, with the applications ranging from non-structural components such as partition walls to mid-rise structural systems. Strength and serviceability checks for these CFS members can be performed using either the Effective Width Method (EWM) or the Direct Strength Method (DSM) which are formally available in design specifications of many parts in the world including North America AISI S100:2016 [1] and Australia AS/NZS 4600:2018 [2]. 
The EWM was originally proposed by von Kármán [3], and slightly re-formulated later by Winter [4] to better predict the strength of CFS members. The method, as suggested by its name, accounts for plate instability by proposing reduced effective-widths where stresses are redistributed after buckling. The EWM provides a conceptually clear and reliable solution to estimate strength of CFS members undergoing local buckling, but it is not well suited to deal with distortional buckling [5]. Further, there are several matters that undermine the method including a complex iterative procedure to determine effective widths and lack of inter-element interaction, i.e. it only considers plate elements individually even though CFS cross-sections in practice are manufactured in complex shapes such as C- and Zsections with and without longitudinal stiffeners.

The DSM approaches instability by a different method. It allows ultimate strength of CFS members to be computed directly using functions of the elastic buckling force, either for local, distortional or global buckling, and the yield force. These two sole input parameters are combined in different forms to predict reasonably the experimental strengths of a wide range of cross-section shapes and sizes undergoing different instability limit states, i.e. local, distortional, global buckling in compression, bending and shear. Reliability analyses show that the DSM is as good as or better than the EWM [6], especially when distortional buckling is the governing limit state. The history of the DSM from its inception and its ongoing development trends have been thoroughly reviewed and discussed from various insightful perspectives by Schafer [6,7] and by Camotim et al. in [5]. These comprehensive reviews also include details regarding the currently active research clusters worldwide.

The current North American Specification for the design of cold-formed steel structural members AISI S100:2016 [1] integrates the DSM in the main specification instead of separating it in an Appendix as in previous 2012 version. The Australian/New Zealand Standard for cold-formed steel structures AS/NZS 4600:2018 [2] has kept the two design methods in parallel in the main body of the standard. For members subjected to shear forces, which are the primary focus of this paper, the DSM design provisions have been incorporated into the AISI Specification since the 2012 version and have recently 
been included in the 2018 edition of the Australian/ New Zealand Standard. The DSM for shear design was proposed by Pham and Hancock [8] on the basis of predominantly shear tests on cold-formed steel plain lipped C-sections and SupaCee ${ }^{\circledR}$ sections. The tests included simply supported beams loaded by a point load at the mid-span to generate a uniform shear force and moment gradient along the shear spans. Shear failure modes, characterised by diagonal shear bands were observed throughout the predominantly shear test series (referred to as V-series) with a shear span aspect ratio (shear-span/webdepth) of 1.0, and are illustrated in Figure 1. The DSM design equations for shear derived from this test series allow the ultimate shear strength $\left(\mathrm{V}_{\mathrm{n}}\right)$ to be computed as follows:

For $\lambda_{v} \leq 0.776$

$$
\mathrm{V}_{\mathrm{n}}=\mathrm{V}_{\mathrm{y}}
$$

For $\lambda_{\mathrm{v}}>0.776$

$$
\mathrm{V}_{\mathrm{n}}=\left[1-0.15\left(\frac{\mathrm{V}_{\mathrm{cr}}}{\mathrm{V}_{\mathrm{y}}}\right)^{0.4}\right]\left(\frac{\mathrm{V}_{\mathrm{cr}}}{\mathrm{V}_{\mathrm{y}}}\right)^{0.4} \mathrm{~V}_{\mathrm{y}}
$$

where

$$
\lambda_{\mathrm{v}}=\sqrt{\frac{\mathrm{V}_{\mathrm{y}}}{\mathrm{V}_{\mathrm{cr}}}}
$$

$\mathrm{V}_{\mathrm{cr}}$ is elastic shear buckling force of the section,

$$
\mathrm{V}_{\mathrm{cr}}=\frac{\mathrm{k}_{\mathrm{v}} \pi^{2} \mathrm{EA}_{\mathrm{w}}}{12\left(1-v^{2}\right)\left(\frac{\mathrm{b}}{\mathrm{t}}\right)^{2}}
$$

where $\mathrm{k}_{\mathrm{v}}$ is shear buckling coefficient for the whole cross-section assuming an average buckling stress in the web, which is given in $[9,10]$ for plain lipped channels, or it can also be estimated by simplified formulae [11] or by manual solution [12]; b is the depth of the flat portion of the web; $\mathrm{t}$ is the thickness of the web; E is Young's modulus and $v$ is Poisson's ratio.

$\mathrm{V}_{\mathrm{y}}$ is the yield shear load of the flat web, 


$$
V_{y}=0.6 f_{y} A_{w}
$$

where $A_{w}$ is the cross-sectional area of the flat web element and $f_{y}$ is the design yield stress

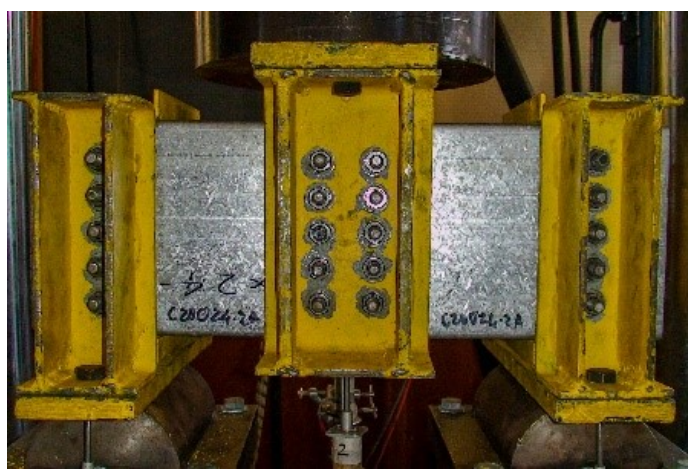

(a) Shear test under loading

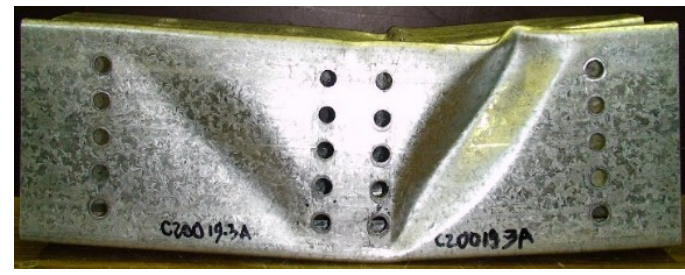

(b) Shear failure mode of a channel

Figure 1: Shear test using conventional test rig

It is emphasised that the DSM design provisions were proposed on the basis of predominantly shear tests with an aspect ratio of 1.0, and with a moment gradient along the shear span. Even though the span is relatively short, the effect of moment on the ultimate shear strength does exist and has not been quantified. Keerthan and Mahendran [13] found that, for the conventional central point load shear tests, full web side plates on both sides of channel webs at the locations of loading and supporting points are required to achieve simply supported boundary conditions. A series of shear tests which adopted this new web side plate configuration was carried out [14] and the DSM design equation (Eq. 2) was slightly modified in which the power coefficient of 0.4 was increased to 0.55 to better fit the test results. However, the use of two rows of bolts at the ends of the shear spans in Keerthan and Mahendran's tests [14] is somewhat controversial as it was pointed out by Pham and Hancock [15] that reduced numbers of bolts decreased postbuckling shear strengths of channel members.

For shear span aspect ratios higher than 1.0, Pham and Hancock [8] conducted a test series with an aspect ratio of 2.0 (referred to as combined bending and shear tests, or MV-series). For these longer shear spans, bending moment became critical and it governed the failure modes at the peak applied shear forces as demonstrated in Figure 2. 


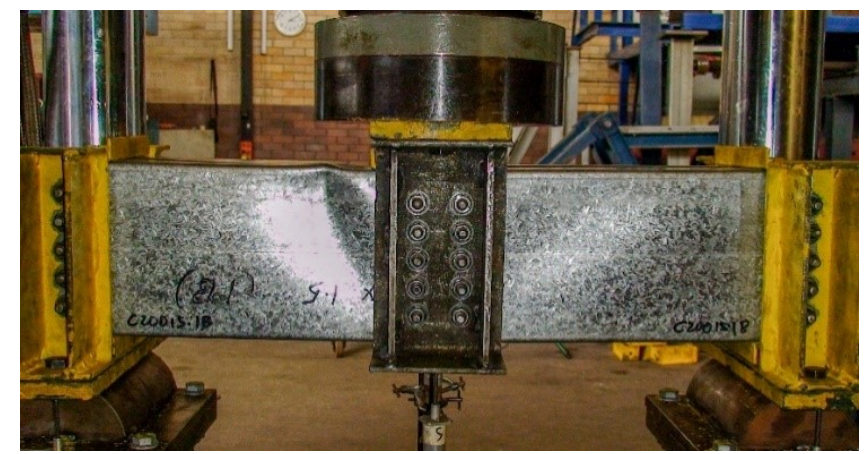

Figure 2: Failure mode of a combined bending and shear test

To design these beams, Pham and Hancock [8] proposed a combined bending and shear approach using a moment and shear interaction curve. The shear capacity of the beams with an aspect ratio of 2.0, an input of the interaction equation, is computed by Eqs. $(1,2)$. In other words, the DSM design rules derived from the tests on beams with an aspect ratio of 1.0 are deemed to be applicable to beams with a higher aspect ratio of 2.0 by deducting the loss in strength caused by bending using the combined bending and shear interaction design equation. Keerthan and Mahendran [14] also carried out combined bending and shear experiments of channel sections with an aspect ratio of 1.5. The experimental results confirmed the validity of the combined bending and shear interaction equation derived by Pham and Hancock [8], and a modified version of the interaction equation was suggested to better fit Keerthan and Mahendran's test data. Although it is evident that the interaction approach is sensible, an experimental verification of the DSM provision of design for members with aspect ratios up to 2.0 is desirable. Previously, the authors developed a test rig, referred to as the Basler rig, to minimize bending moments in shear spans with an aspect ratio of 2.0 [16]. The rig was based on that developed by Basler et al. [17] in the 1960s, which was used to test plate girders in shear. Although this rig is capable of applying the desired shear and moment forces, its implementation with the smaller cold-formed steel members proved to be challenging and possibly cost prohibitive. Hence, a new test rig was developed, as described herein, referred to as the dual actuator rig, which deploys two actuators simultaneously to minimize the bending moment to shear force ratio along the shear spans of interest. The dual actuator rig achieves a similar shear versus moment loading distribution to the Basler rig, but with much simpler specimen preparation and significantly reduced time and cost. Pilot tests showed that the turnaround 
time for each experiment increased up to four-fold. Further, rather than a particular rig designed solely for this type of shear tests, the dual actuator rig provides a powerful testing framework where a desired arbitrary moment-to-shear ratio can be applied to the part of interest of the test specimens. As a result, its applicability can be extended to connection tests, combined bending and shear tests under various moment-to-shear ratios, shear tests with varying moment gradients, and other tests of possible imagination.

In the scope of this paper, two series of tests on cold-formed steel channel sections with aspect ratios of 1.0 and 2.0 were performed using the dual actuator rig. The experimental shear strengths are used together with other available shear test results on beams with aspect ratios of 1.0 [8] and 2.0 [16] to recalibrate the DSM design rules for shear, thus formally confirming their applicability to shear spans with aspect ratios up to 2.0 .

\section{TEST CONFIGURATION}

Despite the numerical feasibility [18], it is a challenge to apply a pure shear force to beam specimens using a standard laboratory loading apparatus. Therefore, the dual actuator test rig aiming to minimize bending effects was developed at the University of Sydney to carry out shear tests of cold-formed steel beam members.

Figure 3(a) shows a schematic drawing of the test setup and the corresponding bending moment and shear force diagrams. Figure 3(b) shows a three-dimensional rendered image of a test in which the front frame is made transparent to offer a clearer view of the test specimen. The test specimen was bolted to a stocky column via $20 \mathrm{~mm}$ thick plates on both the web and the flanges. The two actuators transfer loads to the beam through $20 \mathrm{~mm}$ thick loading plates, which were bolted to the cold-formed steel beam web using five rows of M12 high strength bolts. Each MTS actuator has a capacity of $253 \mathrm{kN}$ in compression and $162 \mathrm{kN}$ in tension, and has a stroke of $508 \mathrm{~mm}$. They are controlled simultaneously by an MTS FlexTest ${ }^{\circledR}$ Controller. The two actuators were able to move independently with different displacement rates $(\mathrm{mm} / \mathrm{min})$; these rates could be adjusted as part of the test protocol. Thus, the 
moments at the two ends of the shear span could be controlled. Figure 4 contains photographs of the overall, the front and the side views of a test on SupaCee ${ }^{\circledR}$ sections with an aspect ratio of 1.0.

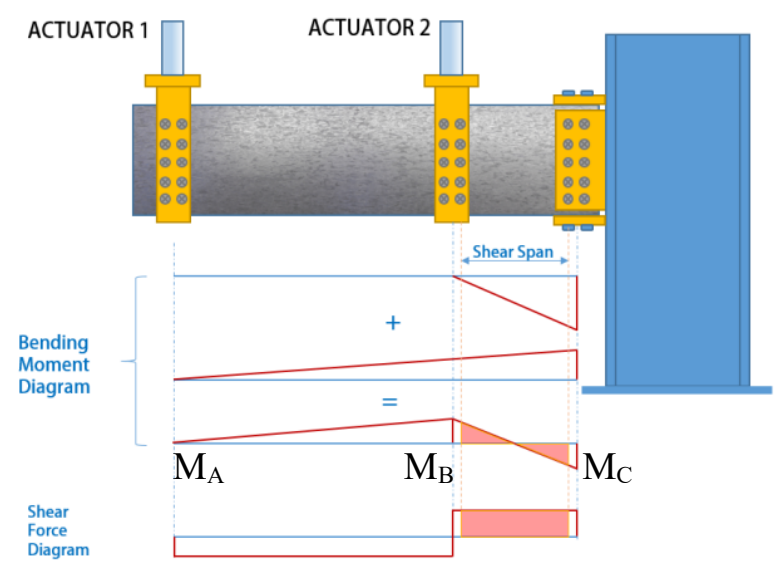

(a) Diagram of test setup

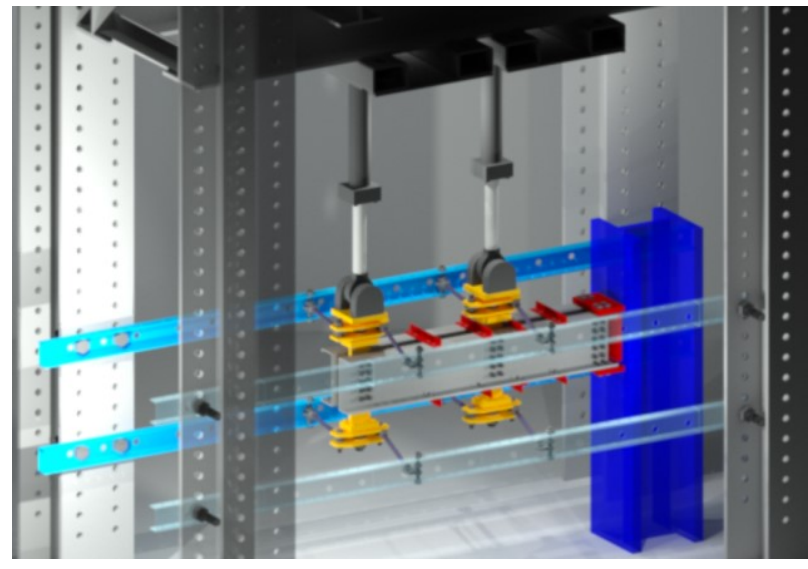

(b) 3D rendered image of the setup

Figure 3: New shear test setup

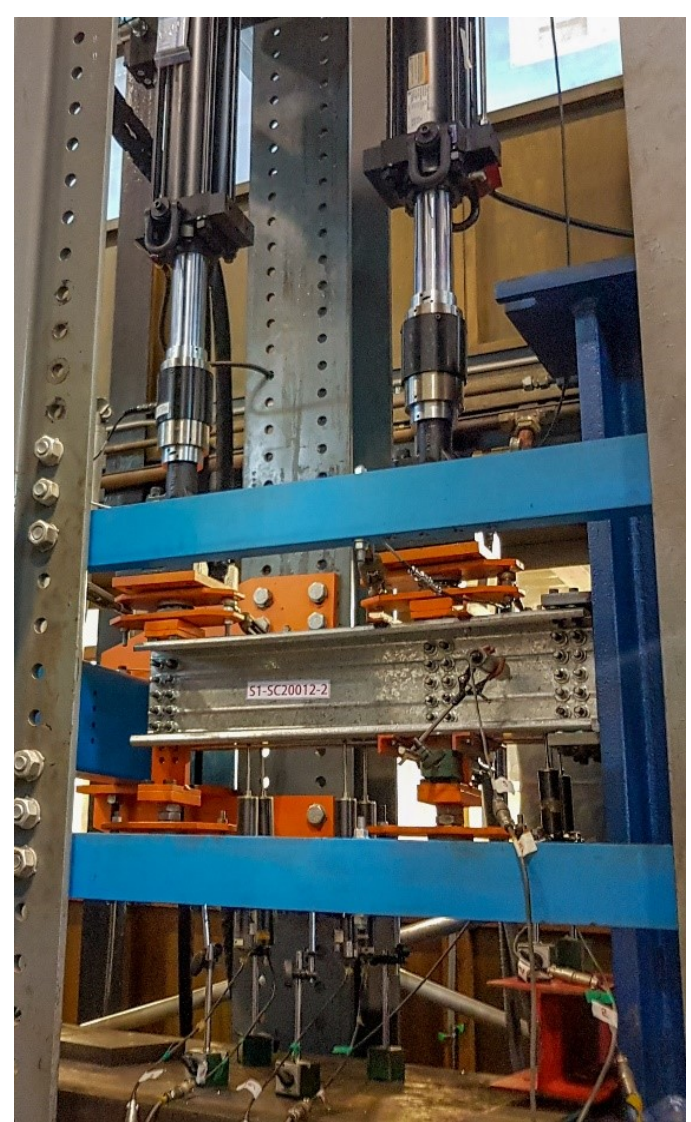

(a) Overall view

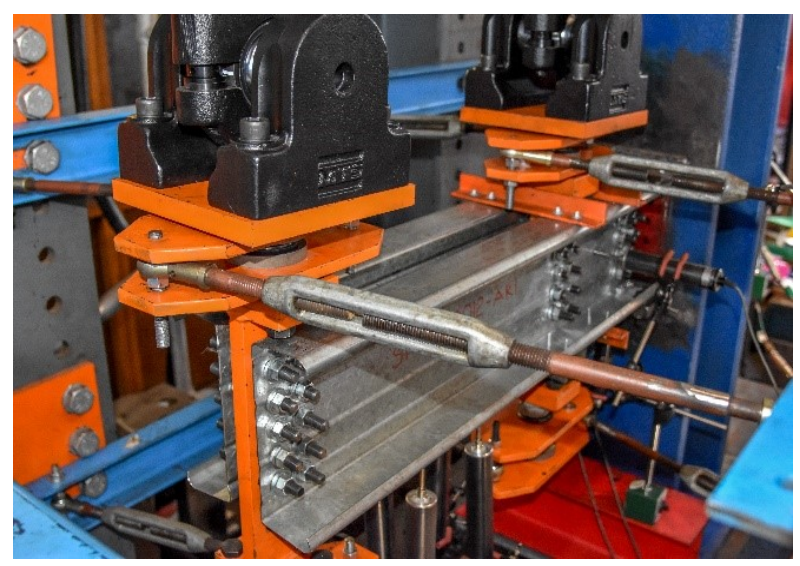

(b) Side view

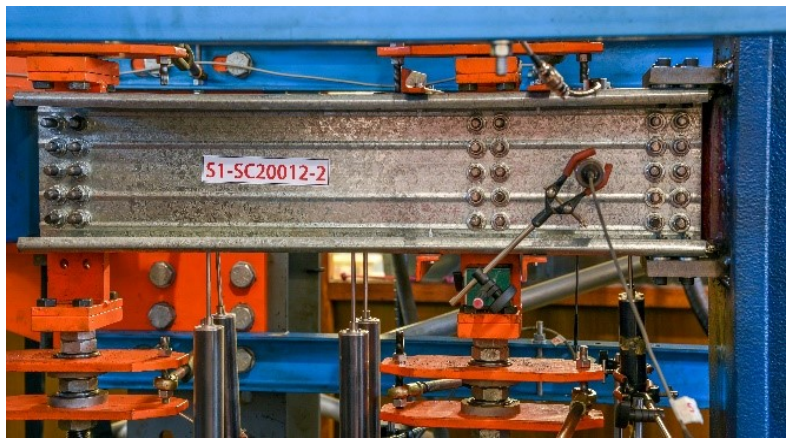

(c) Front view

Figure 4: Shear test on SupaCee ${ }^{\circledR}$ sections 
Each test comprised two steel channel sections bolted to two sides of the loading plates. M16 bolt nuts were used as spacers between these plates and the test specimens to avoid large contact areas, thus more accurate shear span dimension could be achieved. The distortion of the flanges of the two Csection beams was prevented by the straps screwed to both top and bottom flanges, as used by Pham and Hancock [8]. The lateral movement of the system was restrained by two pairs of turnbuckles connected to the top and bottom of each loading plate via horizontal rotation-free plates, as shown in Figure 4(b). The actuators themselves were able to rotate at their ends as a result of hinged connections.

\section{INSTRUMENTATION}

During the tests, ten linear variable differential transformers (LVDTs) were used to track the deformation and displacements of the specimens. Of these, six were used to measure the vertical displacements along the length of the beam and two were mounted to the centre of the shear panel to measure the out-of-plane deformation. The other two LVDTs were used to track the horizontal movement of the column to which the beams were fixed. Further, two inclinometers were attached to the top flanges of the specimen pairs. Forces were measured by means of the $250 \mathrm{kN}$ load cells attached to the actuators. The locations of the instruments are shown in Figure 4(c). Vishay Model 5100B scanners and the Vishay System 5000 StrainSmart software were used to record the measured data.

\section{TEST PROCEDURE}

The aim of the tests was to maintain a bending moment ratio of $M_{C}$ to $M_{B}$ of -1.0 , where $M_{C}$ and $\mathrm{M}_{\mathrm{B}}$, as demonstrated in Figure 3(a), are the moments at the connection and at the other end of the shear span, respectively. At the beginning of each test, a default displacement rate of $0.5 \mathrm{~mm} / \mathrm{min}$ was applied to both actuators, at which the initial ratio of $\mathrm{M}_{\mathrm{C}}$ to $\mathrm{M}_{\mathrm{B}}$ might greatly differ from the target value of 1.0 as demonstrated in Figure 5. Further, during the tests, the rate of change of the moment $\mathrm{M}_{\mathrm{C}}$ at the column connection varied significantly as soon as plastic deformations occurred at the bearing surfaces of the bolt holes in the cold-formed steel beams. The $\mathrm{M}_{\mathrm{C}} / \mathrm{M}_{\mathrm{B}}$ ratio, however, approached the target at 
the onset of the peak shear forces as the displacement rates of the two actuators were adjusted during the tests.

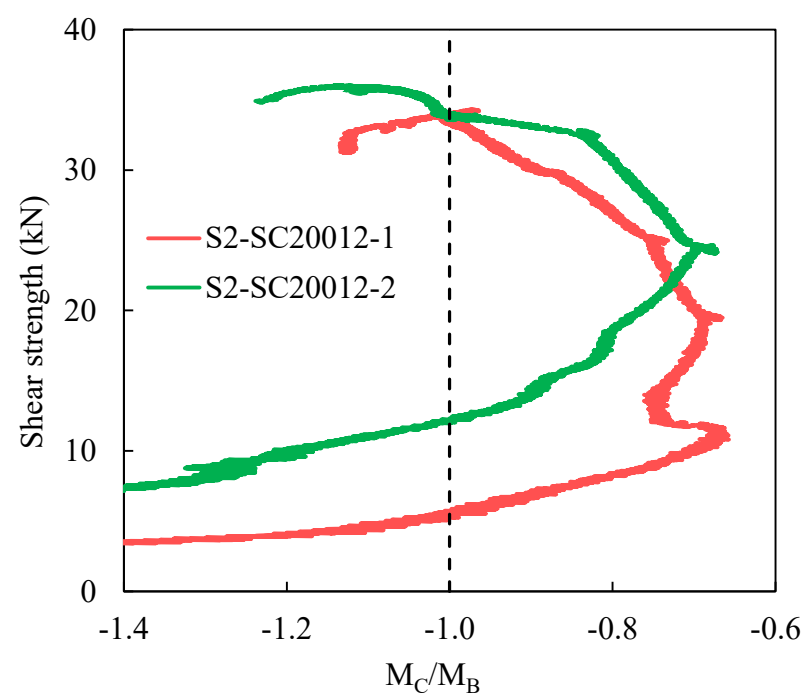

Figure 5: The variation of $\mathrm{M}_{\mathrm{C}} / \mathrm{M}_{\mathrm{B}}$ ratio during shear tests

\section{TEST PROGRAM}

The test program included two series with eight tests in total on high strength cold-formed steel beams with aspect ratios of 1.0 and 2.0 as summarised in Table 1.

Series 1 included four tests, two on G450 [19] plain C and two on G500 [19] SupaCee ${ }^{\circledR}$ cold-formed steel sections, both having an aspect ratio of 1.0, i.e. a $200 \mathrm{~mm}$ shear span. The ultimate shear capacity, in comparison with the central point load test results by Pham and Hancock [8], reveals the influence of bending moment on the shear strength. Since the current DSM design rules for shear were constructed on the basis of the centrally loaded shear tests, the Test Series 1 with minimal bending effects serves as a benchmark to validate these design guidelines.

Series 2 involved two tests on G450 plain C sections and two tests on G500 SupaCee ${ }^{\circledR}$ sections, both with an aspect ratio of 2.0, i.e. a $400 \mathrm{~mm}$ shear span. This series was developed to experimentally confirm the applicability of the DSM for shear capacity to beams with aspect ratios up to 2.0. 
Table 1. Series 1 and 2 test matrix

\begin{tabular}{clccccc}
\hline $\begin{array}{c}\text { Test } \\
\text { series }\end{array}$ & $\begin{array}{c}\text { Test } \\
\text { designation }\end{array}$ & $\begin{array}{c}\text { Shear } \\
\text { span } \\
(\mathrm{mm})\end{array}$ & $\begin{array}{c}\text { Aspect } \\
\text { ratio }\end{array}$ & Section & $\begin{array}{c}\text { Nominal } \\
\text { yield stress } \\
(\mathrm{MPa})\end{array}$ & $\begin{array}{c}\text { Number } \\
\text { of tests }\end{array}$ \\
\hline \multirow{2}{*}{1} & S1-C20015 & 200 & 1.0 & Plain C & 450 & 2 \\
& S1-SC20012 & 200 & 1.0 & SupaCee $^{\circledR}$ & 500 & 2 \\
\hline \multirow{2}{*}{2} & S2-C20015 & 400 & 2.0 & Plain C $^{\circledR}$ & 450 & 2 \\
& S2-SC20012 & 400 & 2.0 & SupaCee $^{\circledR}$ & 500 & 2 \\
\hline
\end{tabular}

The test specimens were labelled to express the series, channel section type, depth and thickness.

Typical test label "S1-C20015-1" is defined as follows:

- 'S1' indicates the test series 1

- 'C200' indicates a channel section with the web depth of $200 \mathrm{~mm}$. Alternately, 'SC' stands for a SupaCee ${ }^{\circledR}$ section.

- '15' indicates the thickness times 10 in $\mathrm{mm}$

- '1' indicates the test number 1 in the Series

The measured dimensions of the plain channel section specimens are given in Table 2, whereas Table 3 lists the measured dimensions of SupaCee ${ }^{\circledR}$ section specimens. The dimensional notations in these two tables are illustrated in Figure 6. The yield stresses $\left(f_{y}\right)$ and Young's modulli $(E)$ of testing specimen materials was determined by tensile coupon tests according to the Australian Standard for metallic materials- Tensile testing at ambient temperature AS 1391-2007 [20].

Table 2. Measured dimensions and yield strength of G450 plain channel section specimens

\begin{tabular}{lccccccc}
\hline Test Designation & $\begin{array}{c}\text { Aspect } \\
\text { ratio }\end{array}$ & $\mathrm{t}(\mathrm{mm})$ & $\begin{array}{c}\mathrm{D} \\
(\mathrm{mm})\end{array}$ & $\begin{array}{c}\mathrm{B}_{\mathrm{C}} \\
(\mathrm{mm})\end{array}$ & $\mathrm{L}(\mathrm{mm})$ & $\mathrm{f}_{\mathrm{y}}(\mathrm{MPa})$ & $\mathrm{E}(\mathrm{MPa})$ \\
\hline \multirow{2}{*}{ S1-C20015-1 } & \multirow{2}{*}{1.0} & 1.51 & 201.6 & 77.23 & 17.07 & 490.0 & 203357 \\
& & 1.52 & 199.3 & 77.18 & 17.89 & $"$ & $"$ \\
S1-C20015-2 & \multirow{2}{*}{1.0} & 1.52 & 200.2 & 77.35 & 17.32 & $"$ & $"$ \\
& & 1.54 & 202.4 & 76.49 & 17.37 & $"$ & $"$ \\
S2-C20015-1 & \multirow{2}{*}{2.0} & 1.53 & 204.1 & 75.55 & 16.25 & 538.9 & 205157 \\
& & 1.54 & 203.5 & 75.80 & 16.03 & $"$ & $"$ \\
S2-C20015-2 & \multirow{2}{*}{2.0} & 1.54 & 204.5 & 75.60 & 16.30 & $"$ & $"$ \\
\hline
\end{tabular}




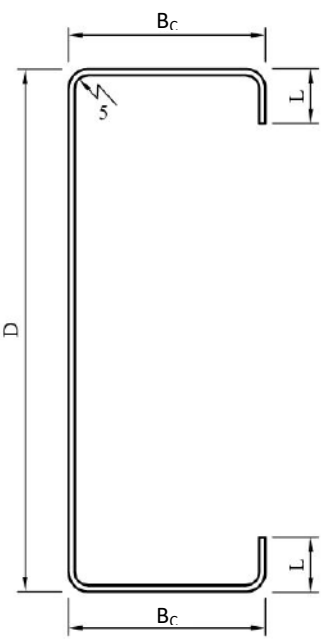

(a) Plain channel section

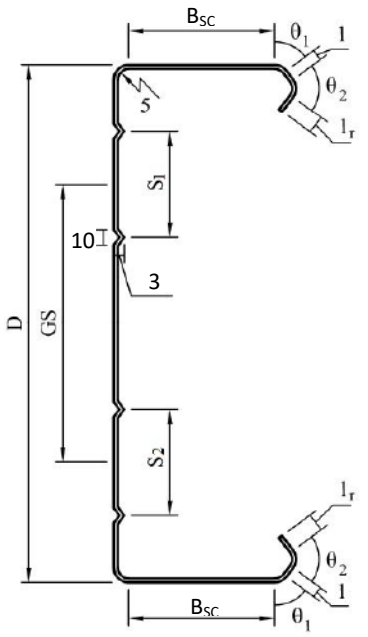

(b) SupaCee section

Figure 6. Dimensions of plain channel section and SupaCee ${ }^{\circledR}$ section $(\mathrm{mm})$

Table 3. Measured dimensions and yield strength of G500 SupaCee ${ }^{\circledR}$ section specimens

\begin{tabular}{lcccccccccccc}
\hline $\begin{array}{l}\text { Test } \\
\text { Designation }\end{array}$ & $\begin{array}{c}\mathrm{t} \\
(\mathrm{mm})\end{array}$ & $\begin{array}{c}\mathrm{D} \\
(\mathrm{mm})\end{array}$ & $\begin{array}{c}\mathrm{B}_{\mathrm{SC}} \\
(\mathrm{mm})\end{array}$ & $\begin{array}{c}1 \\
(\mathrm{~mm})\end{array}$ & $\begin{array}{c}\mathrm{l}_{\mathrm{r}} \\
(\mathrm{mm})\end{array}$ & $\begin{array}{c}\mathrm{G}_{\mathrm{S}} \\
(\mathrm{mm})\end{array}$ & $\begin{array}{c}\mathrm{S}_{1} \\
(\mathrm{~mm})\end{array}$ & $\begin{array}{c}\mathrm{S}_{2} \\
(\mathrm{~mm})\end{array}$ & $\begin{array}{c}\theta_{1} \\
\left({ }^{\circ}\right)\end{array}$ & $\begin{array}{c}\theta_{2} \\
\left({ }^{\circ}\right)\end{array}$ & $\begin{array}{c}\mathrm{f}_{\mathrm{y}} \\
(\mathrm{MPa})\end{array}$ & $\begin{array}{c}\mathrm{E} \\
(\mathrm{MPa})\end{array}$ \\
\hline S1-SC20012-1 & 1.25 & 204.1 & 55.9 & 7.50 & 8.00 & 113.6 & 40.7 & 39.9 & 49.0 & 78.5 & 584.2 & 200951 \\
& 1.23 & 202.6 & 54.6 & 7.10 & 8.30 & 114.0 & 41.3 & 41.2 & 47.5 & 80.5 & $"$ & $"$ \\
S1-SC20012-2 & 1.24 & 205.1 & 54.3 & 7.60 & 7.90 & 111.8 & 42.4 & 42.6 & 46.5 & 77.5 & $"$ & $"$ \\
& 1.23 & 204.5 & 54.2 & 7.20 & 8.20 & 112.4 & 43.1 & 42.8 & 45.5 & 76.0 & $"$ & $"$ \\
\hline S2-SC20012-1 & 1.24 & 205.2 & 55.6 & 7.20 & 8.10 & 112.5 & 42.0 & 40.5 & 48.0 & 77.5 & 584.2 & 200951 \\
& 1.23 & 203.5 & 54.3 & 7.00 & 8.20 & 113.2 & 41.5 & 42.5 & 47.0 & 76.5 & $"$ & $"$ \\
S2-SC20012-2 & 1.24 & 202.5 & 55.0 & 6.90 & 8.10 & 114.5 & 42.2 & 39.5 & 46.5 & 75.5 & $"$ & $"$ \\
& 1.25 & 204.0 & 56.2 & 7.10 & 8.50 & 112.0 & 43.5 & 41.0 & 45.0 & 80.5 & $"$ & $"$ \\
\hline
\end{tabular}

\section{EXPERIMENTAL RESULTS}

\subsection{Test Series 1}

Figure 7 shows the failure mode of a plain channel section having a shear span aspect ratio of 1.0 while under load, and a comparison of the shear failure modes between a plain channel section beam and a SupaCee ${ }^{\circledR}$ section beam, also having a shear span aspect ratio of 1.0. The shear band spans diagonally at the shear span, which is identical to an idealized pure shear failure. Even though the buckling mechanisms are dissimilar between the two section types, referred to a roof buckling [21] for the plain C and a flip-disc buckling [21] for the SupaCee ${ }^{\circledR}$, only one shear band was observed for both. The shear failure modes are similar to those obtained by Pham and Hancock $[8,22]$ as shown in Figure 
1(b) except for the fact that much less buckling deformation at the top flange due to bending was observed. This further supports the close-to-shear state generated by the new test rig.
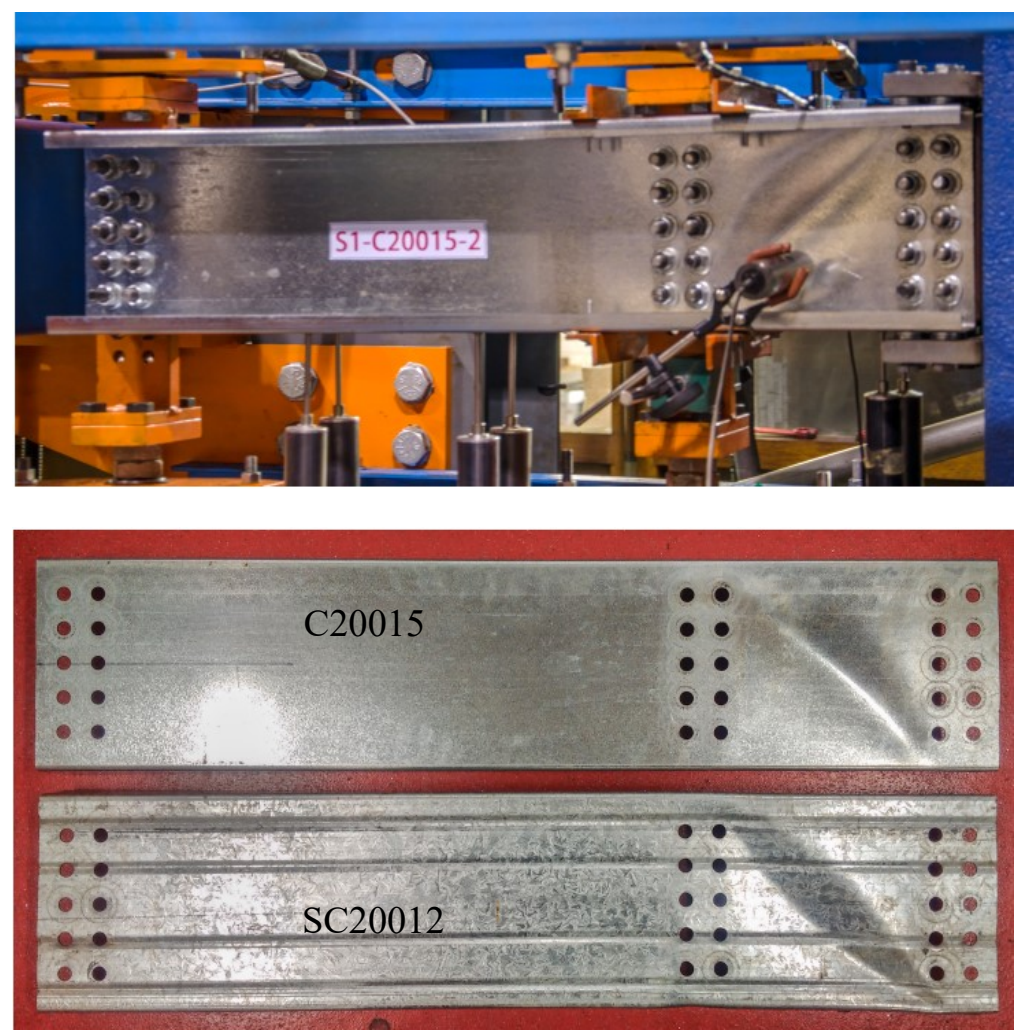

Figure 7: Shear failure modes of beams with an aspect ratio of 1.0

The peak shear forces, $V_{T}$, can be seen in Table 4. It is noted that $V_{T}$ is the ultimate shear capacity of a single channel. In this table, the average experimental results by Pham and Hancock [8] for the same aspect ratio and section sizes, but with the conventional central point load tests, are included. Because of the difference in the material yield stresses, the shear strength is normalised to the shear loads at yielding $\left(\mathrm{V}_{\mathrm{y}}\right)$ to facilitate the comparison between the two tests series. $\mathrm{V}_{\mathrm{y}}$ is computed on the basis of the measured yield stresses. The normalisation is performed on the average values for Pham's and Hancock's tests. The ratios of the maximum moments to shear forces along the length of the shear spans are also determined for each test series, where $\mathrm{M}_{\mathrm{T}, \max }$ is the maximum of the absolute values of $\mathrm{M}_{\mathrm{B}}$ and $\mathrm{M}_{\mathrm{C}}$. While the ratios are a constant for the $\mathrm{V}$-series by virtue of the determinate nature of the test setup, they slightly vary in the Test Series 1 due to the change of the connection stiffness which was dealt with by adjusting the rates of the actuators. 
Table 4. Experimental results - Series 1

\begin{tabular}{|c|c|c|c|c|c|c|c|c|}
\hline \multirow{2}{*}{$\begin{array}{c}\text { Test } \\
\text { Designation }\end{array}$} & \multirow{2}{*}{$\begin{array}{l}\text { Shear } \\
\text { Span } \\
(\mathrm{mm})\end{array}$} & \multirow{2}{*}{$\begin{array}{l}\text { Aspect } \\
\text { Ratio }\end{array}$} & \multicolumn{3}{|c|}{ Test Series 1} & \multicolumn{3}{|c|}{$\begin{array}{c}\text { V-Series } \\
\text { (Pham and Hancock [8]) }\end{array}$} \\
\hline & & & $\begin{array}{c}\mathrm{V}_{\mathrm{T}} \\
(\mathrm{kN})\end{array}$ & $\mathrm{V}_{\mathrm{T}} / \mathrm{V}_{\mathrm{y}}$ & $\begin{array}{l}\mathrm{M}_{\mathrm{T}, \max } / \mathrm{V}_{\mathrm{T}} \\
(\mathrm{m})\end{array}$ & $\begin{array}{l}\mathrm{V}_{\mathrm{T}, \mathrm{avg}} \\
(\mathrm{kN})\end{array}$ & $\begin{array}{l}\mathrm{V}_{\mathrm{T} \text {,avg }} \\
/ \mathrm{V}_{\mathrm{y}, \mathrm{avg}}\end{array}$ & $\begin{array}{l}\mathrm{M}_{\mathrm{T}} / \mathrm{V}_{\mathrm{T}} \\
(\mathrm{m})\end{array}$ \\
\hline S1-C20015-1 & 200 & 1.0 & 52.5 & 0.63 & 0.114 & \multirow{2}{*}{55.9} & \multirow{2}{*}{0.63} & \multirow{2}{*}{0.20} \\
\hline S1-C20015-2 & 200 & 1.0 & 54.3 & 0.64 & 0.115 & & & \\
\hline S1-SC20012-1 & 200 & 1.0 & 44.2 & 0.53 & 0.117 & \multirow{2}{*}{46.5} & \multirow{2}{*}{0.56} & \multirow{2}{*}{0.20} \\
\hline S1-SC20012-2 & 200 & 1.0 & 45.6 & 0.55 & 0.115 & & & \\
\hline
\end{tabular}

The normalised shear strength shows that there is little difference, up to a maximum of $5.7 \%$, between the shear strengths obtained by the Test Series 1 using the dual actuator test rig and by the V-series using the conventional central point load test configuration. Taking the moment-to-shear ratios into consideration, it can be seen that although the dual actuator testing apparatus induced a ratio of approximately a half of the one produced by the conventional test rig, the shear strength obtained from the two series was essentially similar despite slight variations. This proves that, for the tests with an aspect ratio of 1.0, the influence of bending moments on the shear strengths is negligible.

\subsection{Test Series 2}

Figure 8 compares the failure modes of a plain $C$ and a SupaCee ${ }^{\circledR}$ section member, both having a shear span aspect ratio of 2.0, where the diagonal shear bands were clearly observed. These shear failure modes are distinct from the combined bending and shear failure mode of the shear span having the same aspect ratio as shown in Figure 2. Even at this high aspect ratio, no flange distortion was observed at the peak shear forces as opposed to the failure mode produced by the conventional central point load test rig as seen in Figure 1(b). 


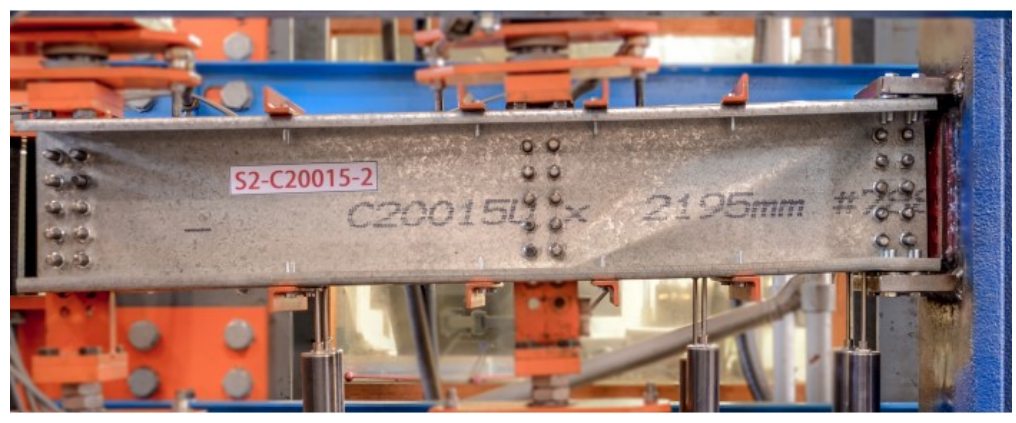

(a) Plain C

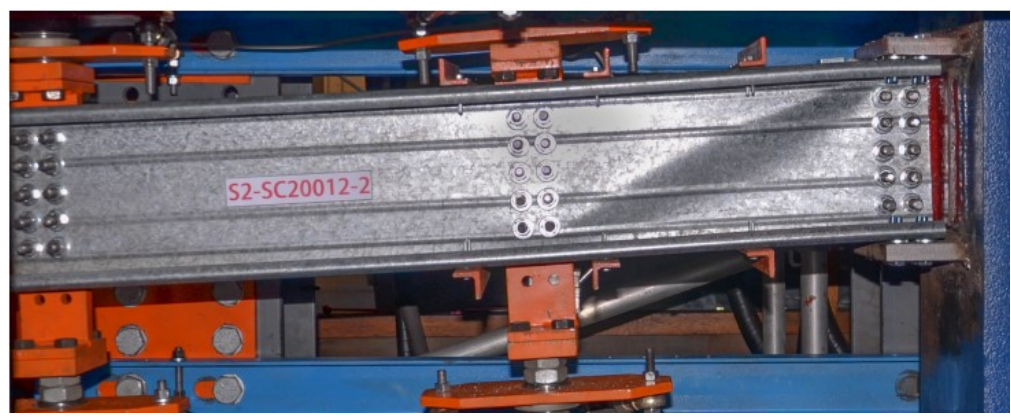

(b) SupaCee ${ }^{\circledR}$

Figure 8: Shear failure modes of beams with an aspect ratio of 2.0

The test results are given in Table 5, along with the average experimental results obtained by Pham and Hancock [8] using the conventional central load tests, which involved twice the moment to shear ratio produced by the new rig. All the notations are explained previously.

Table 5. Experimental results - Series 2

\begin{tabular}{|c|c|c|c|c|c|c|c|c|}
\hline \multirow{2}{*}{$\begin{array}{c}\text { Test } \\
\text { Designation }\end{array}$} & \multirow{2}{*}{$\begin{array}{l}\text { Shear } \\
\text { Span } \\
(\mathrm{mm})\end{array}$} & \multirow{2}{*}{$\begin{array}{l}\text { Aspect } \\
\text { Ratio }\end{array}$} & \multicolumn{3}{|c|}{ Test Series 2} & \multicolumn{3}{|c|}{$\begin{array}{c}\text { MV-Series } \\
\text { (Pham and Hancock [8]) }\end{array}$} \\
\hline & & & $\begin{array}{c}\mathrm{V}_{\mathrm{T}} \\
(\mathrm{kN})\end{array}$ & $\mathrm{V}_{\mathrm{T}} / \mathrm{V}_{\mathrm{y}}$ & $\begin{array}{c}\mathrm{M}_{\mathrm{T}, \max } / \mathrm{V}_{\mathrm{T}} \\
(\mathrm{m})\end{array}$ & $\begin{array}{l}\mathrm{V}_{\mathrm{T}, \mathrm{avg}} \\
(\mathrm{kN})\end{array}$ & $\begin{array}{l}\mathrm{V}_{\mathrm{T} \text {,avg }} \\
\mathrm{V}_{\mathrm{y} \text {,avg }}\end{array}$ & $\begin{array}{c}\mathrm{M}_{\mathrm{T}} / \mathrm{V}_{\mathrm{T}} \\
\quad(\mathrm{m})\end{array}$ \\
\hline S2-C20015-1 & 400 & 2.0 & 47.8 & 0.51 & 0.212 & \multirow{2}{*}{34.2} & \multirow{2}{*}{0.36} & \multirow{2}{*}{0.40} \\
\hline S2-C20015-2 & 400 & 2.0 & 47.5 & 0.50 & 0.213 & & & \\
\hline S2-SC20012-1 & 400 & 2.0 & 34.3 & 0.41 & 0.213 & \multirow{2}{*}{27.1} & \multirow{2}{*}{0.33} & \multirow{2}{*}{0.40} \\
\hline S2-SC20012-2 & 400 & 2.0 & 36.1 & 0.43 & 0.224 & & & \\
\hline
\end{tabular}

The normalised shear strength as shown in Table 5 encapsulates a substantial shear capacity enhancement, as high as $41.6 \%$ for plain $\mathrm{C}$ sections and $30.3 \%$ for SupaCee ${ }^{\circledR}$ sections, when the moments were significantly reduced. However, in comparison with the Test Series 1, the ultimate shear 
forces reduce by $10.7 \%$ and $21.6 \%$ for plain $\mathrm{C}$ and SupaCee ${ }^{\circledR}$ section respectively. This reduction is partially attributed to the lesser contribution of the shear buckling strengths of the longer shear panels.

\section{VALIDATION AND RE-CALIBRATION OF THE DSM FOR SHEAR}

The test results are normalized to the shear yield loads, $V_{y}$, and the section slenderness $\left(\lambda_{\mathrm{v}}\right)$ is computed and summarized in Table 6 for the two test series. The elastic shear buckling loads are determined using the BFINST8 program [23], which accounts for the cross-section as a whole and simply supported end boundary conditions. A pure shear loading scenario is adopted in this program for the buckling analyses. This is consistent with the method used by Pham and Hancock [8] to derive the DSM equations for shear design. The shear yield loads are computed on the basis of Eq. (4) with the yield stress determined from the coupon tests. $\mathrm{V}_{\mathrm{n}, \mathrm{DSM}}$ is the shear strength predicted by the DSM shear design provisions, i.e. they are computed by using Eqs. $(1,2)$. The accuracy of the predictions was verified by comparing with the experimental results as shown in the last column in Table 6 . The test-to-predicted ratios prove a good agreement with a coefficient of variation $(\mathrm{CoV})$ of $5.5 \%$. However, for the Test Series 1, a better agreement is observed with the average ratio just slightly above 1.0. Meanwhile, the average ratio is equal to 0.93 for the Test Series 2 .

Table 6. Shear capacity of Series 1 and 2 test specimens

\begin{tabular}{|c|c|c|c|c|c|c|c|c|c|}
\hline $\begin{array}{c}\text { Test } \\
\text { Designation }\end{array}$ & $\begin{array}{l}\text { Shear } \\
\text { Span } \\
(\mathrm{mm})\end{array}$ & $\begin{array}{c}\text { Aspect } \\
\text { Ratio }\end{array}$ & $\begin{array}{c}\mathrm{V}_{\mathrm{T}} \\
(\mathrm{kN})\end{array}$ & $\begin{array}{l}\mathrm{V}_{\mathrm{cr}} \\
(\mathrm{kN})\end{array}$ & $\begin{array}{l}\mathrm{V}_{\mathrm{y}} \\
(\mathrm{kN})\end{array}$ & $\lambda_{\mathrm{V}}$ & $\begin{array}{l}\mathrm{V}_{\mathrm{T}} / \\
\mathrm{V}_{\mathrm{y}}\end{array}$ & $\begin{array}{c}\mathrm{V}_{\mathrm{n}, \mathrm{DSM}} \\
(\mathrm{kN})\end{array}$ & $\begin{array}{c}\mathrm{V}_{\mathrm{T}} / \\
\mathrm{V}_{\mathrm{n}, \mathrm{DSM}}\end{array}$ \\
\hline S1-C20015-1 & 200 & 1.0 & 52.5 & 32.1 & 83.5 & 1.61 & 0.63 & 51.1 & 1.03 \\
\hline S1-C20015-2 & 200 & 1.0 & 54.3 & 33.0 & 84.7 & 1.60 & 0.64 & 52.1 & 1.04 \\
\hline S1-SC20012-1 & 200 & 1.0 & 44.2 & 21.6 & 83.0 & 1.96 & 0.53 & 44.2 & 1.00 \\
\hline S1-SC20012-2 & 200 & 1.0 & 45.6 & 21.7 & 83.3 & 1.96 & 0.55 & 44.3 & 1.03 \\
\hline S2-C20015-1 & 400 & 2.0 & 47.8 & 24.3 & 94.7 & 1.97 & 0.51 & 50.2 & 0.95 \\
\hline S2-C20015-2 & 400 & 2.0 & 47.5 & 24.3 & 95.2 & 1.98 & 0.50 & 50.3 & 0.94 \\
\hline S2-SC20012-1 & 400 & 2.0 & 34.3 & 14.6 & 83.1 & 2.39 & 0.41 & 38.3 & 0.90 \\
\hline S2-SC20012-2 & 400 & 2.0 & 36.1 & 15.0 & 83.3 & 2.36 & 0.43 & 38.7 & 0.93 \\
\hline & & & & & & & \multicolumn{2}{|c|}{ Mean } & 0.98 \\
\hline & & & & & & & \multicolumn{2}{|c|}{ SD } & 0.05 \\
\hline & & & & & & & \multicolumn{2}{|c|}{$\mathrm{CoV}(\%)$} & 5.54 \\
\hline
\end{tabular}




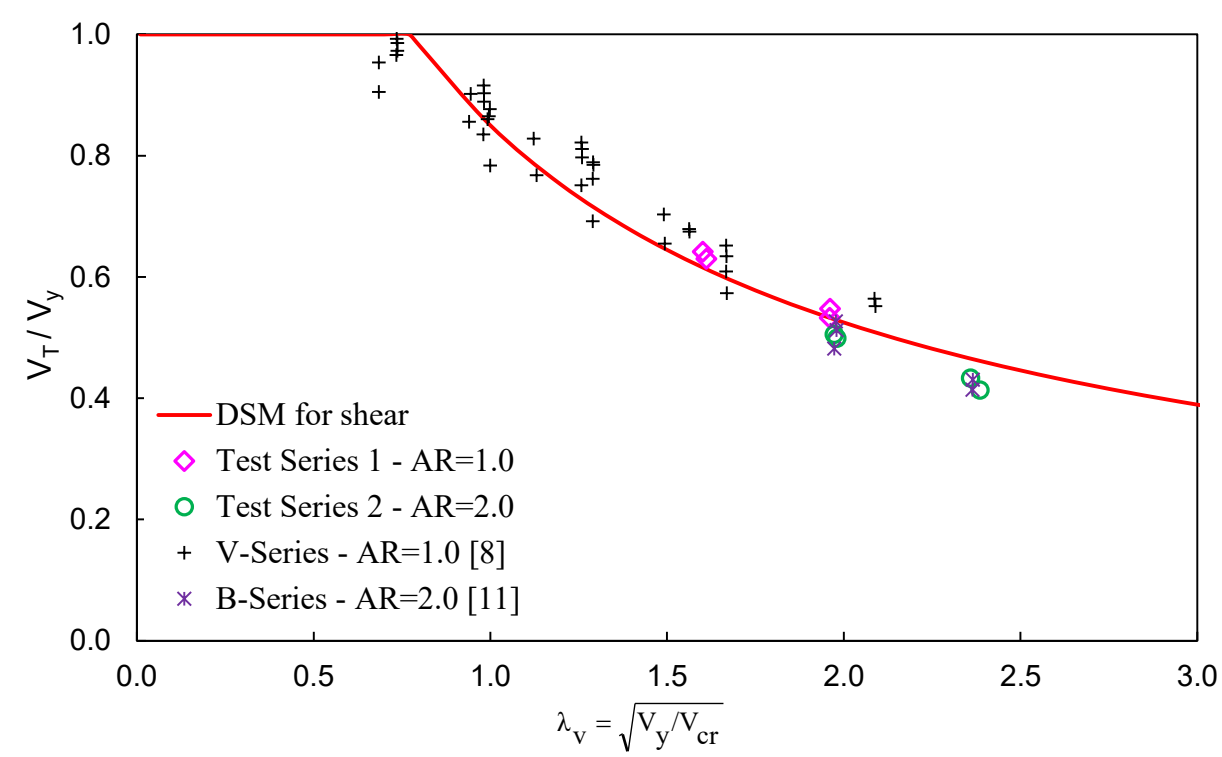

Figure 9. Experimental results plotted against the DSM design curve

The non-dimensional data in Table 6 is plotted against the DSM design curve for shear as shown in Figure 9. The shear test outcomes on beams with an aspect ratio of 1.0 conducted by Pham and Hancock [8] are also included. It is noted that this data was used to derive the DSM shear curve in the AISI S100:2016 and AS/NZS 4600 standards. Since Pham and Hancock [8] did not incorporate their tests on the beams with the aspect ratio of 2.0 (MV-Series) into the calibration of the DSM for shear, this test series is excluded from Figure 9. In general, the data follows well the design curve. Therefore, it can be concluded that, overall, this DSM curve is applicable to predict shear strength of beams with aspect ratios up to 2.0. The good match of the test results for beams with an aspect ratio of 1.0 indicates that for the short beams, the effects of bending moments are minimal, thus the central point load tests are acceptable for shear study. The data points for tests on beams with an aspect ratio of 2.0 follow well the design curve and thus affirm its applicability. However, the data locates slightly under the shear curve presumably due to the existence of the minimal bending moments and/or due to the fact that the curve was proposed based solely on shear tests with an aspect ratio of 1.0. Figure 10 shows the test-topredicted ratios in relation with the section slenderness for the shear tests with the aspect ratios of 1.0 and 2.0. The associated mean value and the standard deviation are 1.012 and 0.064 respectively. 


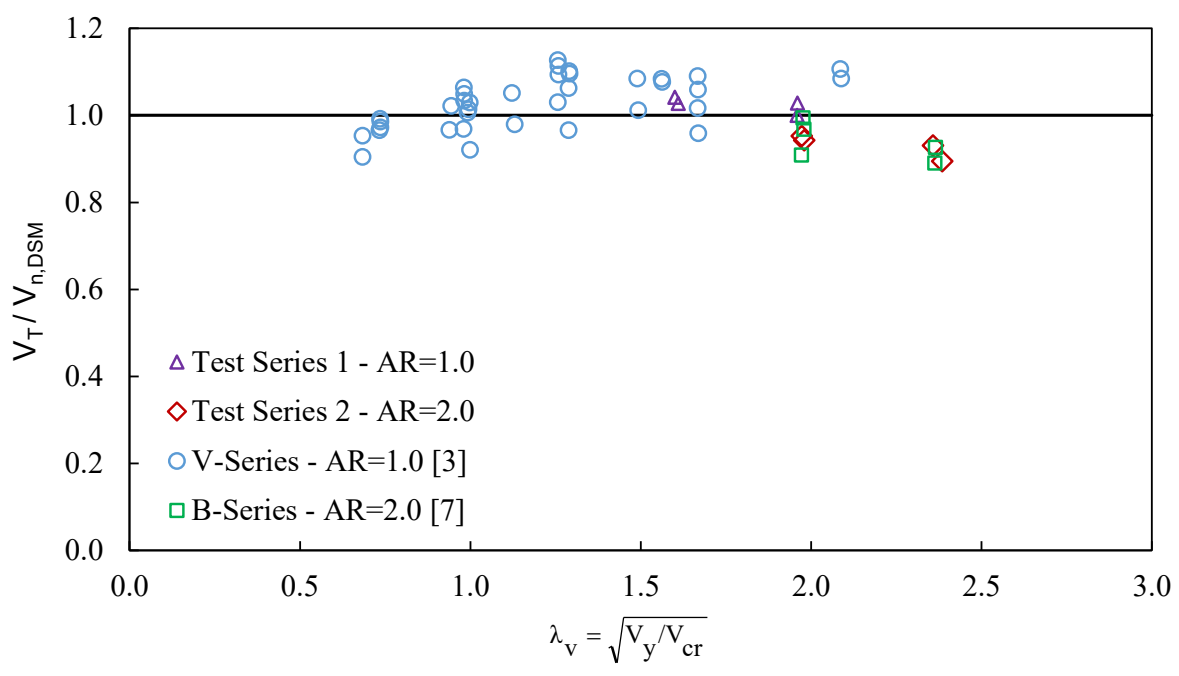

Figure 10. Test-to-predicted ratios for shear tests

The resistance factor $(\phi)$ associated with the shear strength determined by the DSM as per Eqs. (1) and (2) is computed using the AISI S100-16 Eq. K2.1.1-2 as follows:

$$
\phi=C_{\phi}\left(M_{m} F_{m} P_{m}\right) e^{-\beta_{o} \sqrt{V_{M}^{2}+V_{F}^{2}+C_{P} V_{P}^{2}+V_{Q}^{2}}}
$$

where

$\mathrm{M}_{\mathrm{m}}$ is the mean value of material factor with its associated coefficient of variation of $\mathrm{V}_{\mathrm{M}}$;

$\mathrm{F}_{\mathrm{m}}$ is the mean value of fabrication factor with its associated coefficient of variation of $\mathrm{V}_{\mathrm{F}}$;

$\mathrm{P}_{\mathrm{m}}$ is the mean value of professional factor taken as 1.012 as mentioned previously;

$V_{P}$ is the coefficient of variation of test results, computed as the ratio of standard deviation of testto-predicted ratios to $\mathrm{P}_{\mathrm{m}}$. These to values are mentioned previously, thus $\mathrm{V}_{\mathrm{P}}$ takes a value of 0.063 but a minimum value of 0.065 is adopted as per the specification;

$\mathrm{V}_{\mathrm{Q}}$ is the coefficient of variation of load effect, taken as 0.21 for the Load and Resistance Factor Design (LRFD) as specified by the AISI S100-16;

$C_{P}$ is the correction factor, $C_{P}=\left(1+\frac{1}{n}\right) m /(m-2)$, where $n=49$ is the number of tests, $m=n-1=48$ is the degree of freedom; as a result, $\mathrm{C}_{\mathrm{P}}=1.065$. 
For the LRFD, the calibration coefficient $\left(C_{\phi}\right)$ is taken as 1.52 , and the target reliability index $\left(\beta_{\mathrm{o}}\right)$ is 2.5 for structural members. The values of $\mathrm{M}_{\mathrm{m}}, \mathrm{V}_{\mathrm{M}}, \mathrm{F}_{\mathrm{m}}$ and $\mathrm{V}_{\mathrm{F}}$ are $1.192 ; 0.031 ; 1.000$ and 0.010 respectively. These values are taken from 1,207 tests for steels from $1.0 \mathrm{~mm}$ to $3.0 \mathrm{~mm}$ over a 12 -month period from the mill of Bluescope Steel Ltd [8]. These are compared with the set of values extracted in the AISI S100-16 of $1.100 ; 0.100 ; 1.000$ and 0.050 which show that statistical actual results obtained by Bluescope Steel Ltd are slightly higher and more consistent. With the target reliability index of 2.5, a resistance factor $(\phi)$ of 1.05 is obtained, which is greater than the factor of 0.95 in the AISI S100-16 and of 0.9 in the AS/NZS 4600:2018.

\section{CONCLUSION}

This paper summarises the experimental program on plain C and SupaCee ${ }^{\circledR}$ cold-formed steel sections undergoing shear forces and minimal bending moments. The test results were used to validate the DSM design provisions for shear as originally proposed by Pham and Hancock [8], and as currently found in AISI S100:2016 and AS/NZS 4600. The new test rig powered by two independent actuators with adjustable rates enables an effective control of the moments at the two ends of the shear span. As a result, the effect of the moment was managed and minimized. The test results affirmed the applicability of the DSM design provisions for shear for members with shear span aspect ratios up to 2.0. All available shear test results on cold-formed steel channel sections with aspect ratios of 1.0 and 2.0 are used to re-calibrate the DSM design rules for shear. A resistance factor $(\phi)$ of 1.05 is obtained corresponding to a target reliability index of 2.5. As a result, it is confirmed that the current resistance factor of 0.95 for shear strength as per the AISI S100-16 and 0.9 in the AS/NZS 4600:2018 are applicable to the shear strength predicted by the DSM. 


\section{ACKNOWLEDGEMENT}

Funding provided by the Australian Research Council Discovery Project Grant DP160104640 has been used to perform this project. The first author is supported by the University of Sydney International Scholarship.

\section{REFERENCES}

[1] AISI, North American Specification for the Design of Cold-Formed Steel Structural Members, S10016th ed., Washington, D.C, U.S.A, 2016.

[2] Standards Australia, AS4600 Cold-formed steel structures, in: Standards Australian/Standards New Zealand, 2018.

[3] V. Kármán, T., Strength of thin plates in compression, Trans. ASME. 54 (1932) 53-57.

[4] G. Winter, Strength of thin steel compression flanges, Trans. ASCE. 112 (1947) 527-576.

[5] C. Yu, Recent Trends in Cold-Formed Steel Construction, Woodhead Publishing, 2016.

[6] B.W. Schafer, Review: The Direct Strength Method of cold-formed steel member design, J. Constr. Steel Res. 64 (2008) 766-778. doi:10.1016/j.jcsr.2008.01.022.

[7] B.W. Schafer, Advances in the direct strength method of thin-walled steel design, in: Eighth Int. Conf. THIN-WALLED Struct. ICTWS 2018, Lisbon, Portugal, 2018.

[8] C.H. Pham, G.J. Hancock, Direct Strength Design of Cold-Formed C-Sections for Shear and Combined Actions, J. Struct. Eng. ASCE. 138 (2012) 759-768. doi:10.1061/(ASCE)ST.1943-541X.0000510.

[9] C.H. Pham, G.J. Hancock, Shear buckling of thin-walled channel sections, J. Constr. Steel Res. 65 (2009) 578-585. doi:10.1016/j.jcsr.2008.05.015.

[10] C.H. Pham, G.J. Hancock, Elastic buckling of cold-formed channel sections in shear, Thin-Walled Struct. 61 (2012) 22-26.

[11] P. Keerthan, M. Mahendran, Shear buckling characteristics of cold-formed steel channel beams, Int. J. Steel Struct. 13 (2013) 385-399. doi:10.1007/s13296-013-3001-6.

[12] K. Aswegan, C.D. Moen, Critical Elastic Shear Buckling Stress Hand Solution for C- and Z-Sections Including Cross-Section Connectivity, in: Twenty-First Int. Spec. Conf. Cold-Formed Steel Struct., St. Louis, Missouri, U.S.A., 2012: pp. 223-231.

[13] P. Keerthan, M. Mahendran, Experimental studies on the shear behaviour and strength of LiteSteel beams, Eng. Struct. 32 (2010) 3235-3247. doi:10.1016/J.ENGSTRUCT.2010.06.012.

[14] P. Keerthan, M. Mahendran, Experimental investigation and design of lipped channel beams in shear, Thin-Walled Struct. 86 (2015) 174-184. doi:10.1016/j.tws.2014.08.024. 
[15] C.H. Pham, G.J. Hancock, Tension field action for cold-formed sections in shear, J. Constr. Steel Res. 72 (2012) 168-178. doi:10.1016/j.jcsr.2011.12.001.

[16] S.H. Pham, C.H. Pham, G.J. Hancock, Experimental study of shear strength of cold-formed channels with an aspect ratio of 2.0, J. Constr. Steel Res. 149 (2018) 141-152. doi:10.1016/J.JCSR.2018.07.002.

[17] K. Basler, B.-T. Yen, J.A. Mueller, B. Thürlimann, Web buckling tests on welded plate girders, Part 3: Tests on plate girders subjected to shear, Bethlehem, Pennsylvania, 1960.

[18] S.H. Pham, C.H. Pham, G.J. Hancock, Direct strength method of design for shear including sections with longitudinal web stiffeners, Thin-Walled Struct. 81 (2014) 19-28. doi:10.1016/j.tws.2013.09.002.

[19] Standards Australia, AS 1397-2011. Continuous hot-dip metallic coated steel sheet and strip - Coatings of zinc and zinc alloyed with aluminium and magnesium, (2011).

[20] Standards Australia, AS 1391-2005. Metallic materials- Tensile testing at ambient temperature, (2005).

[21] N.W. Murray, Introduction to the theory of thin-walled structures, Clarendon Press Oxford, Oxfordshire, 1984.

[22] C.H. Pham, Direct Strength Method (DSM) of Design of Cold Formed Sections in Shear, and Combined Bending and Shear, The University of Sydney, 2010.

[23] G.J. Hancock, C.H. Pham, Shear buckling of channel sections with simply supported ends using the semi-analytical finite strip method, Thin-Walled Struct. 71 (2013) 72-80.

doi:10.1016/j.tws.2013.05.004. 